\title{
Aeolian sediment availability in coastal areas defined from sedimentary parameters. Application to a case study in Fuerteventura*
}

\author{
J. ALCÁNTARA-CARRIÓ ${ }^{1}$ and I. ALONSO ${ }^{2}$ \\ ${ }^{1}$ Departamento de Geociencias Marinas y O. T., Universidad de Vigo, 36200 Vigo, Spain. \\ ${ }^{2}$ Departamento de Física. Universidad de Las Palmas de Gran Canaria, 35080 Las Palmas de Gran Canaria, Spain.
}

\begin{abstract}
SUMMARY: Wind characteristics and availability of airborne sediments control aeolian dynamics. Availability of sediments has been only estimated from dune dimensions. Nevertheless, this method is not valid in serir (stone dessert) and sand sheets deposits, where surface properties better than volume of materials define their sediment availability. The area chosen for this study is the Isthmus of Jandía (Fuerteventura, Canary Islands), which presents a high diversity of present day aeolian environments. Grain-size and compositional parameters from surface samples permit the design of its sedimentary cartography, which shows spatial and seasonal variations of the aeolian dynamics. Values of these parameters have been combined by statistical analyses to obtain a new parameter, lineal combination of mean size, sorting, skewness, and carbonate content, which has been named the Aeolian Sediment Availability (ASA) parameter. The ASA parameter presents several advantages over the previous mobility diagrams (mean size $v s$ sorting), since it considers more sedimentary variables, has a continuous numerical gradient which permits the plotting of maps of the aeolian sediment availability, and has a clear physical meaning. Dynamics inferred from this parameter are satisfactory compared with local wind data, empirical transport rates and landscape unit maps of the area.
\end{abstract}

Key words: aeolian sediment transport, availability, wind, grain-size parameters, carbonate content, Fuerteventura.

\section{INTRODUCTION}

The relationship between wind energy and sediment properties defines aeolian sand transport. Many other environmental factors modify this process in coastal dunes, such as vegetation, humidity content, topography, and human actions (Sherman and Hotta, 1990), but two basic conditions are i) wind exceeding a threshold shear stress and ii) availability of sediments to be blown. Wind characteristics have been extensively studied: vertical velocity profiles (Bagnold, 1941, Bauer et al.,

*Received June 12, 2000. Accepted September 3, 2000.
1992), interaction with dune forms (Bennett and Best, 1995), meteorological influences (Frank and Kocurek, 1994), etc. Source areas are identified from textural and compositional criteria. However physical models of aeolian sand transport derived from wind tunnel and field observations (e.g. Bagnold, 1941, 1956; Hsu, 1973; Horikawa et al., 1986) do not consider restrictions in the mobility of sediments caused by an inadequate aeolian sediment supply (Williams and Lee, 1995). We present a new concept closely related to the previous one, which is that of aeolian sediment availability (ASA). It is important to distinguish between them. Aeolian sediment supply (ASS) refers to the sediment volume 
arriving from a source area, which can be evaluated from inputs of sediments to the study area and erosion rates at the source area, while ASA is the instantaneous amount of sediments ready to be blown at a certain time and place, and has been normally considered as unlimited in the classical transport models (Sarre, 1988; Dingler et al., 1992).

Different authors working with dunes have proposed several parameters to account for the sediment movement (Howard et al., 1978; Hesp and Hastings, 1998). Wasson and Hyde (1983) defined the Equivalent Sand Thickness (EST) parameter as the thickness of a continuous sheet of sand that results from the hypothetical spreading out of dunes over a specified area. According to these authors, dune forms are a function of both wind direction variability (RDP/DP parameter of Fryberger and Dean, 1979) and EST (Fig. 1). Nevertheless dune forms are minorities in many aeolian coastal environments in which sand sheets and serir deposits are predominant and the EST parameter cannot be applicable.

Study area is composed by a great combination of aeolian sedimentary environments, including dunes, sand sheets and serir deposits. Surface sediments of these deposits can be characterised by their textural and compositional parameters. Textural and compositional variables usually used in grain-scale studies are the grain-size parameters (mean size, sorting, skewness and kurtosis) and the specific gravity. Mean grain size is widely employed in dynamic interpretations, transport equations and sedimentary environment differentiation, with medium sand as the typical size of mobile dunes (Bagnold, 1941). Sorting is very useful in aeolian dynamic studies: well-sorted sediments are characteristics of dune deposits while serir deposits are poorly sorted (Reineck and Singh, 1980). Skewness is likewise used to describe grain size distributions in aeolian environments and models to pattern the sediment transport trends (Le Roux, 1994). Finally, kurtosis is the less employed grain size parameter, and even Friedman (1961) affirms that it is not an environment-sensitive parameter. In relation to compositional analysis, density is the other parameter that determines if the sediments will be blown. An increase in density means more difficulty to take off and be blown. Chemical and mineralogical composition can also be used as an indicator of density, because both are strongly related, and compositional analyses permit the identification of the source areas of sediments. In fact, carbonate content is a parameter extensively employed.

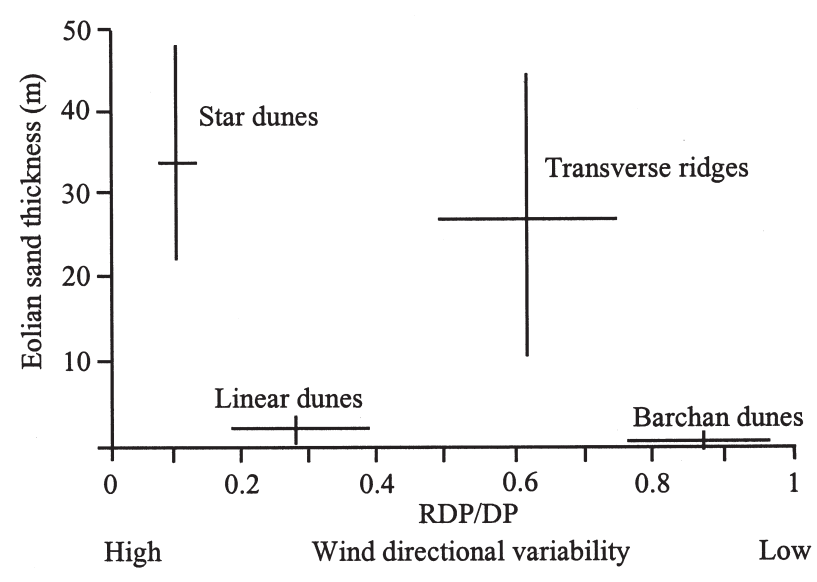

FIG. 1. - Equivalent sand thickness versus wind directional variability to four elemental dune kinds (After Wasson and Hyde, 1983).

Friedman (1961) proposed a diagram of mean size $v s$ sorting to discriminate between aeolian and fluvial desert environments. After this diagram Besler (1983) defined the Response Diagram, which plots the grain-size limits between aeolian mobility, aeolian stability, aeolian residuals and fluvial sediments for desert sediments. Aeolian mobility is characteristic of surface sand deposits with high aeolian transport. Aeolian stability corresponds to sediments with an appropriate grain size to be blown but poorly sorted, and consequently, associated aeolian transport is not too relevant. Finally, aeolian residuals refer to mixed deposits from fine to very coarse grains, typical of deflation surfaces where high roughness impairs the movement of finer grains. Different limits of the Response Diagram were proposed by Gläser (1984).

The goal of this work is to show that grain properties of the surface sediments define the Aeolian Sediment Availability (ASA) of these areas, rather than the volume of sediments. Textural and compositional parameters have been analysed in order to characterise the aeolian surface deposits of Jandía isthmus and to obtain its sedimentary cartography. Principal Component Analysis (PCA) and Multiple Regression Analysis (MRA) permit the combination of most of the information of the considered variables in two new statistical parameters, where only one of them is related to the aeolian sediment availability. Ranges of this parameter have been proposed and plotted. Resulting maps are compared with the sedimentary cartography and previous studies in the area of wind, landscape unit map, empirical rates of transport and aeolian flux diagrams (Alcántara-Carrió et al., 1996). 


\section{MATERIAL AND METHODS}

\section{Study area}

Jandía isthmus, located in the southwest of Fuerteventura, is the biggest aeolian area of the Canary Islands with an area of $54.2 \mathrm{~km}^{2}$, mostly constituting the Natural Park of Jandía. The rest of the area and beaches are an important tourist resort. The isthmus has a smooth slow relief, with a mean height of $130 \mathrm{~m}$ and a maximum elevation at Lomas Negras (322 m). Other outstanding hills are Risco del Paso (253 m), Agua Oveja (213 m) and Montañeta de los Verodes (154 m). These low dome hills consist of volcanic materials covered with carbonate crusts in many cases. Slope differences are mainly between windward and lee side, but most of the isthmus $(83 \%)$ has a gentle slope $\left(<8^{\circ}\right)$. Vegetal cover is very variable across the isthmus. Typical plants are shrubs, but there is also an important seasonal increase of grass dependent upon irregular rains during the winter. The study area is semiarid, with less than 200 liters $/ \mathrm{m}^{2}$ per year.

Seasonally, two periods have been described for the local wind behaviour (Alcántara-Carrió et al., 1996): i) Trade winds blowing from May to September, with medium-high speed and N-NE direction, but the local topography modifies it to N-NW on the bottom layer of the study area, and ii) during the rest of the year or autumn-winter period, wind

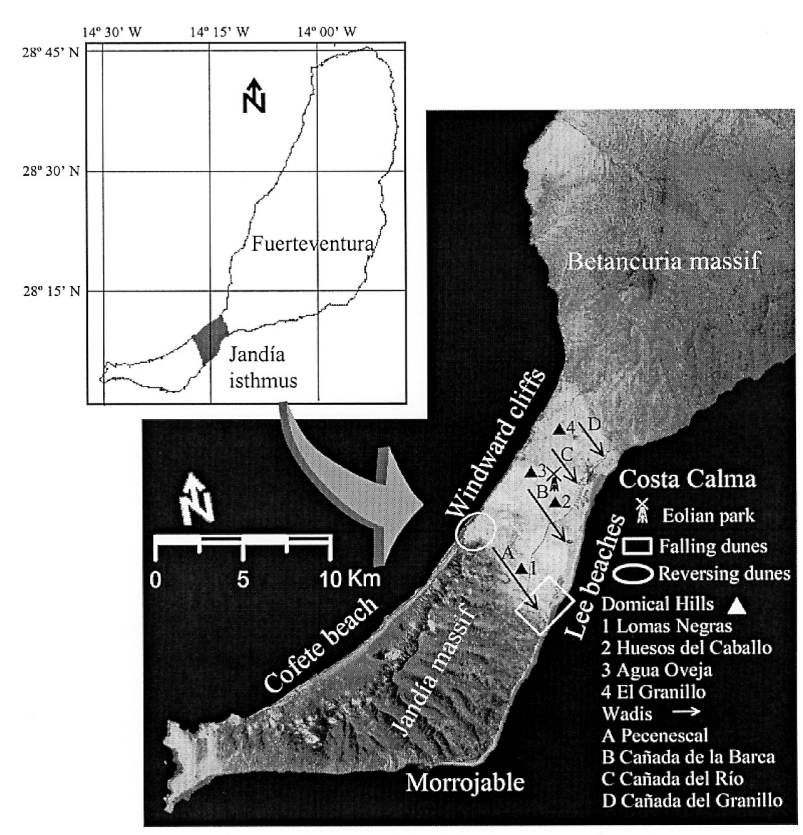

FIG. 2. - Location of the study area and aerial photograph of Jandía Isthmus. presents a high variability both in speed and direction. Spatial differences in the wind velocity however are not significant (Calero and Cartas, 1990).

The isthmus surface presents a wide diversity of ancient and modern aeolian environments intercalated with carbonate crust, volcanic outcrops and alluvial deposits. A landscape unit map obtained from aerial photographs of 1992 (E. 1:50,000) identifies the different sedimentary units, whose extensions have been calculated by GIS techniques (AlcántaraCarrió et al.,1996; Alonso et al., 1998). Serir areas are mainly located on the top of hillocks (e.g. Lomas Negras and Cañada del Granillo), while alluvial compacted clays are located at the bottom of some wadies. Nevertheless, most of surface sediments actually covering the isthmus are white biogenic sands eroded from ancient dunes (Fig. 2). Higher dunes (more that $100 \mathrm{~m}$ long and $8 \mathrm{~m}$ high) are located in the southwestern limit of the isthmus, without any vegetal cover. Finally, the majority of aeolian deposits of the isthmus are sand sheets with different thickness and superimposed dune forms, associated with vegetation. The windward coastal limit of the isthmus is a cliff $11.6 \mathrm{~km}$ long and over $30 \mathrm{~m}$ high, while the lee coast consists mainly of long sandy beaches with a tidal flat and sand barrier. Limits of the isthmus with Jandía and Betancuria massifs are easily deduced from aerial photographs (Fig. 2).

Messinian and Jandian terraces have been identified on the isthmus. During the following marine regressions, both Pliocene and Upper Pleistocene dune deposits were formed by the trade winds blowing over the windward marine deposits. Pliocene deposits are actually exposed in windward cliffs, which reach up to 30-m thickness in some areas and are covered by a carbonated crust. Pleistocene deposits have been identified in the Huesos del Caballo hillside, near the middle of the study area (Meco, 1993). Geomorphologic, textural and mineralogical studies show that there is no actual supply of marine sediments from the windward coast to the isthmus. In contrast, the source of present aeolian sediment transport is aeolian surface erosion itself (Alcántara-Carrió, 1999).

\section{Sampling and laboratory procedures}

Two sampling surveys were carried out in August 1996 (109 samples) and February 1997 (132 samples), according to seasonal wind pattern. For each period all the aeolian environments have been 
sampled in both windward and leeward sides: i.e. serir, sand sheet and dune areas. Surface samples were located by GPS and taken from upper 0-30 mm (after Lancaster, 1986).

Samples were dry sieved at $0.5 \phi$ intervals from $-4 \phi$ to $4.5 \phi$, percent weight data plotted and graphic grain-size parameters calculated following Folk and Ward (1957). Grain-size distributions have permitted the identification of samples with one, two or more modes. Carbonate content of medium sand (1$2 \phi)$ and gravel (around $-3 \phi$ ) fractions have been obtained by Bernard's volumetric method (Guitián and Carballas, 1976), like compositional indicator of the different modes.

Maps have been plotted for each sampling period and parameter (mean size, sorting, skewness, kurtosis and carbonate content). The topography of the maps has been digitalized from the National Geographic Service (scale 1:25,000) and volcanic outcrops blanked. Surfer programme has been used to interpolate from samples to draw each map according to the classical grain size criteria (Folk and Ward, 1957; Friedman and Sanders, 1978). Carbonate content maps have used 5\% intervals for classification. Grid data of each parameter and survey have been statistically analysed.

\section{Statistical analysis}

Maps analysis shows main spatial and seasonal patterns in the surface sediment properties, which will define three preliminary zones with a very different behaviour. Values of the five variables considered in this sedimentary cartography (mean size, sorting, skewness, kurtosis, and carbonate content) for each sample have been combined by means of a principal component analysis (PCA) method, which has been repeated twice, one for each sampling period. This statistical method obtains, from initially correlated variables, a minor number of new factors that are not correlated, and makes analysis easier without loosing significant information.

The new factors, their auto-values and percent of total associated variance have been obtained by

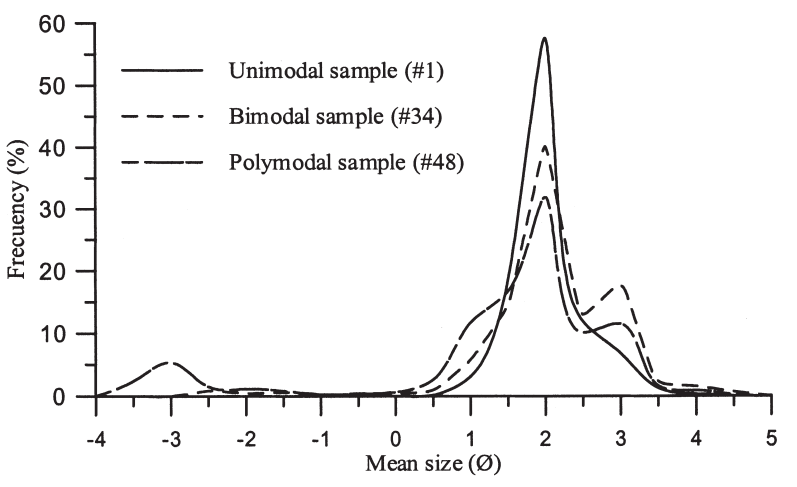

FIG. 3. - Histogram of unimodal, bimodal and polymodal grain-size distributions. Data from three samples of August 1996. This distributions correspond with mobile samples, stable samples and aeolian residuals of Gläser (1994) respectively.

means of SPSS statistical programme. The only factors to be considered are those with an auto-value higher than 1. From PCA, a value of each factor for each one of the different samples has been obtained. This information, linked to the values of the original variables, has been coupled in a multiple regression analysis (MRA) where mean size, sorting, skewness, kurtosis and carbonate content have been used as independent variables and each extracting factor as a dependent variable. In this way, the resultant factors can be expressed as a linear combination of the initial variables, so that each equation shows the mathematical relation between each extracting factor and the sedimentological variables. R-squared coefficients between factors extracted from the PCA and factors calculated by the MRA are equal to 1 .

\section{RESULTS}

\section{Textural and compositional parameters}

Grain size distributions show that there are samples with one, two and three modes at each survey, but they have always the main mode around $2 \phi$ fraction. Secondary modes, with more than $5 \%$ wt, have been identified in $3 \phi$ and $-3 \phi$ fractions (Fig. 3). Average values of graphic grain-size parameters are very similar in both study periods, and correspond to

TABLE 1. - Average values and standard deviation of graphic grain-size parameters and carbonate content for each survey.

\begin{tabular}{|c|c|c|c|c|c|c|}
\hline \multirow[t]{2}{*}{ Survey } & \multicolumn{4}{|c|}{ Grain-size parameters $(\phi)$} & \multicolumn{2}{|c|}{ Carbonate content (\%) } \\
\hline & Mean size & Sorting & Skewness & Kurtosis & Gravel & Mean sand \\
\hline August 1996 & $1.43 \pm 0.09$ & $1.01 \pm 0.10$ & $-0.09 \pm 0.05$ & $1.08 \pm 0.39$ & $61,87 \pm 5,50$ & $86,29 \pm 1,28$ \\
\hline February 1997 & $1.51 \pm 0.08$ & $1.05 \pm 0.09$ & $-0.12 \pm 0.04$ & $1.28 \pm 0.08$ & $64,69 \pm 4,86$ & $90,71 \pm 0,96$ \\
\hline
\end{tabular}



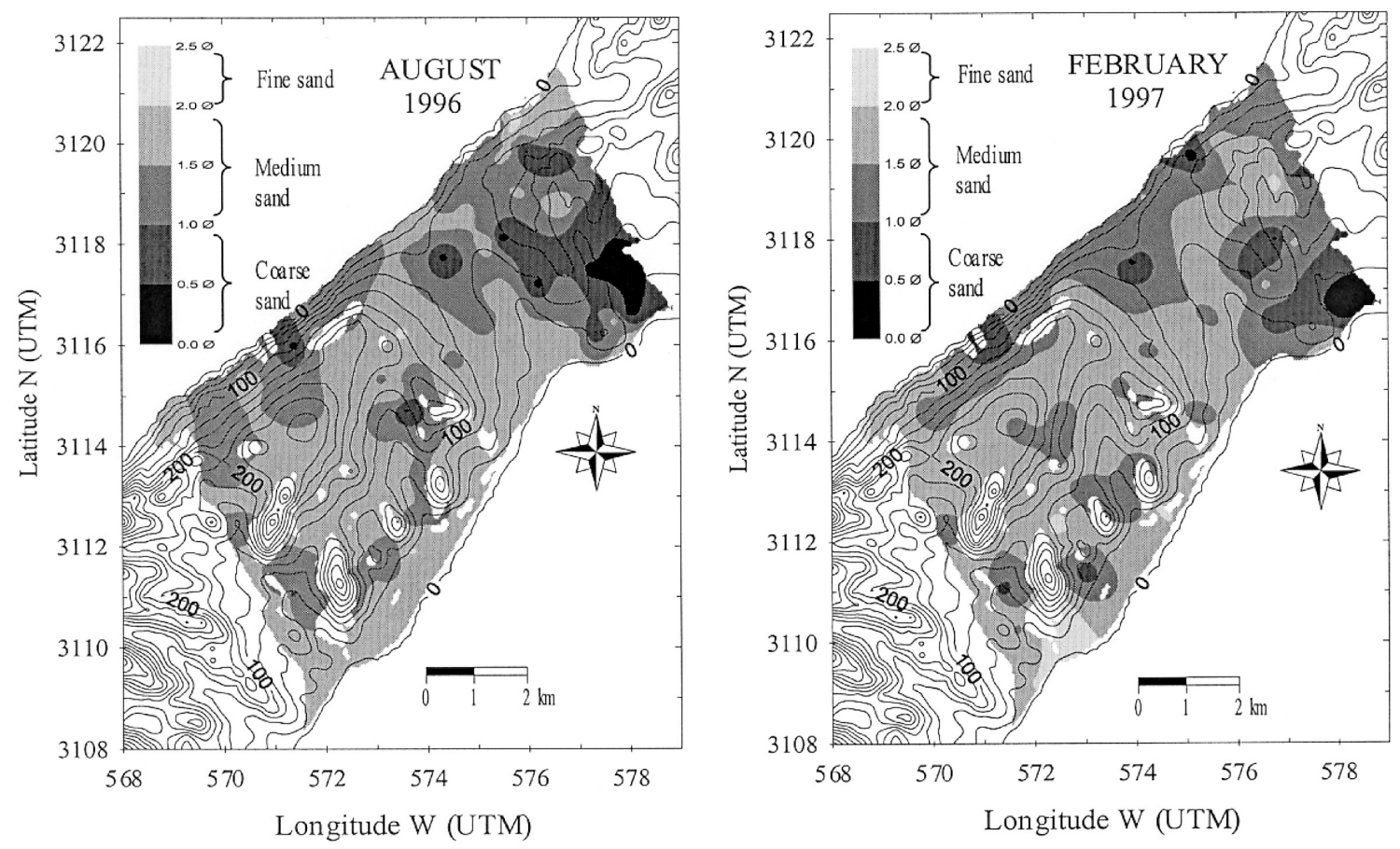

FIG. 4. - Mean grain size maps at Jandía isthmus for August 1996 and February 1997.

TABLE 2. - Isthmus surface percentages associated with different intervals of the maps.

\begin{tabular}{|c|c|c|c|}
\hline \multirow[t]{2}{*}{ Class } & \multirow[t]{2}{*}{ Range } & \multicolumn{2}{|c|}{ Isthmus surface $(\%$} \\
\hline & & $\begin{array}{c}\text { August } \\
1996\end{array}$ & $\begin{array}{c}\text { February } \\
1997\end{array}$ \\
\hline \multicolumn{4}{|l|}{ Mean size } \\
\hline \multirow{3}{*}{ Mean sand } & $2 \phi<\mathrm{M}_{7}<2.5 \phi$ & 1.93 & 2.68 \\
\hline & $1.5 \phi<\mathrm{M}^{\mathrm{z}}<2 \phi^{\mathrm{T}}$ & 51.62 & 54.04 \\
\hline & $1 \phi<\mathrm{M}_{2}^{\mathrm{z}}<1.5 \phi$ & 34.00 & 33.66 \\
\hline \multirow{2}{*}{ Coarse sand } & $0.5 \phi<\mathrm{M}^{\mathrm{z}}<1 \phi$ & 10.63 & 8.31 \\
\hline & $0 \phi<\mathrm{M}_{\mathrm{z}}^{2}<0.5 \phi$ & 1.82 & 1.30 \\
\hline \multicolumn{4}{|l|}{ Sorting } \\
\hline Very Poorly & $2 \phi<\sigma_{\mathrm{I}}<4 \phi$ & 3.36 & 3.73 \\
\hline \multirow[t]{2}{*}{ Poorly } & $1.5 \phi<\sigma_{\mathrm{I}}<2 \phi$ & 11.75 & 17.33 \\
\hline & $1 \phi<\sigma<1.5 \phi$ & 22.93 & 33.38 \\
\hline Middle & $0.5 \phi<\sigma_{\mathrm{I}}<1 \phi$ & 55.47 & 38.87 \\
\hline Well & $0.35 \phi<\sigma_{\mathrm{I}}<0.5 \phi$ & 6.49 & 6.70 \\
\hline \multicolumn{4}{|l|}{ Skewness } \\
\hline Very positively & $0.3 \phi<\mathrm{Sk}_{\mathrm{I}}<1 \phi$ & 1.25 & 0.36 \\
\hline Positively & $0.1 \phi<\mathrm{Sk}_{\mathrm{I}}<0.3 \phi$ & 9.12 & 7.82 \\
\hline Symmetrical & $-0.1 \phi<\mathrm{Sk}_{\mathrm{J}}<0.1 \phi$ & 45.52 & 35.46 \\
\hline Negatively & $-0.3 \phi<\mathrm{Sk}_{\mathrm{I}}<-0.1 \phi$ & 28.69 & 29.83 \\
\hline Very negatively & $-1 \phi<\mathrm{Sk}_{\mathrm{J}}<-0.3 \phi$ & 15.42 & 26.52 \\
\hline
\end{tabular}

medium, poorly sorted, nearly symmetrical, and leptokurtic or very leptokurtic sand (Table 1).

Mean grain size maps show a general predominance of medium sand, except for the northeastern area, where coarse sands are predominant. Medium sand is coarser in the windward side. Significant seasonal variations have not been identified for this parameter (Fig. 4 and Table 2).

Sorting presents a high spatial and temporal variability (Fig. 5 and Table 2). Well-sorted sediments are only present in the southwestern limit. Moderately sorted sediments are predominant in the southwestern and central areas, ranging from $55.47 \%$ to $38.87 \%$ of the total surface for August 1996 and February 1997 respectively. Finally, poorly sorted sediments are located in the northeastern area. There is a general increase of sorting values for the winter, which denotes higher variability in grain size.

Skewness also shows a high variability at the study area (Fig. 6). Northeastern zone of the isthmus is very negatively or negatively skewed in both study periods, but during the winter the total percentage of this value range increases (Table 2). Small zones with positive skewness are permanently located in the southwestern and northern limits of the isthmus, but another one appears at the western limit in August.

Comparison of sorting and skewness sample data is interesting because well-sorted sediments are positively skewed, while poorly sorted ones have negative values in both study periods ( $\mathrm{R}$-squared equal to 0.73 and 0.63 for August 1996 and February 1997, respectively).

Kurtosis maps are shown in Figure 7. Most of the surface corresponds to leptokurtic sediments in both periods, and mesokurtic ones are more abundant in the trade winds period (see also Table 1). Only one area with platikurtic values is placed in the northeastern limit of the isthmus. 

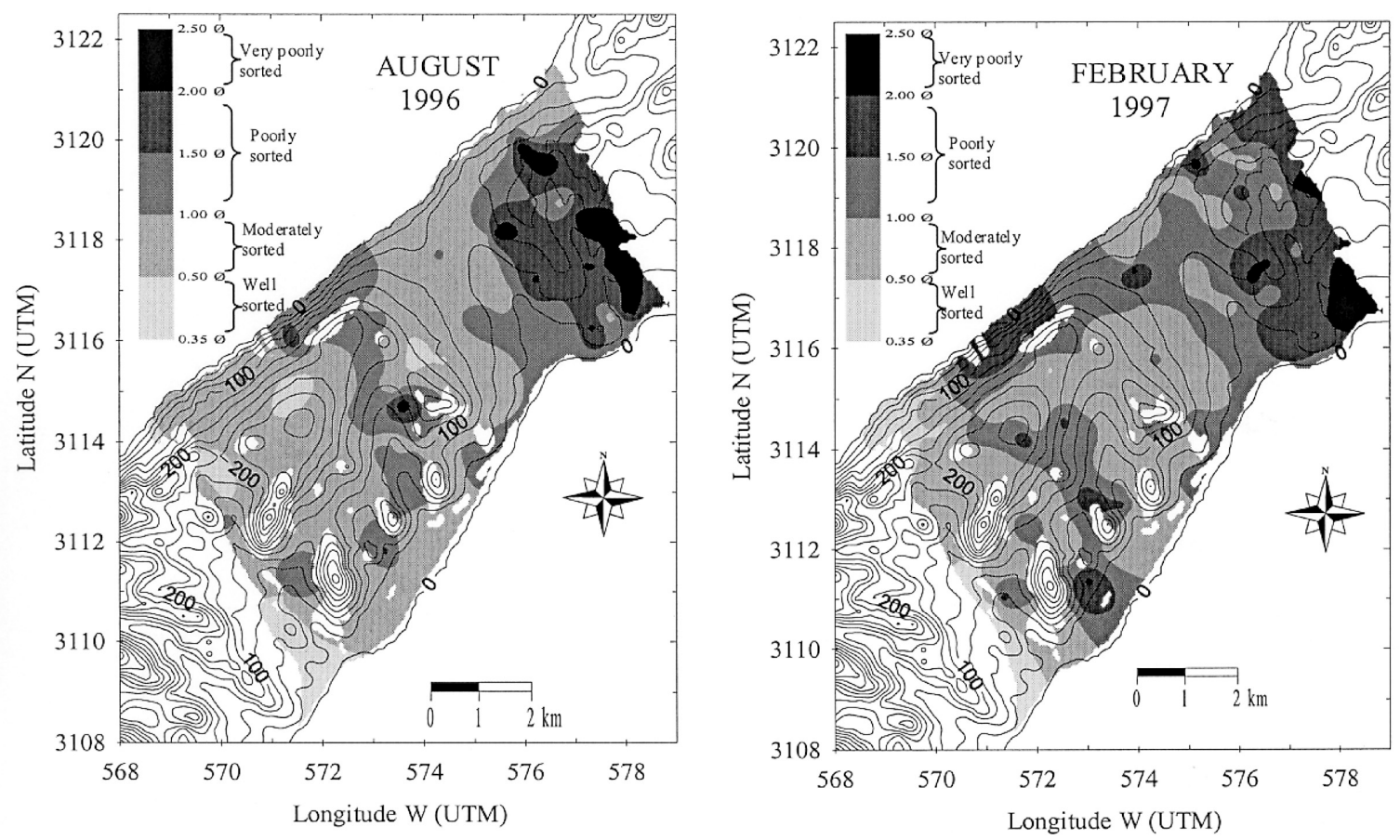

FIG. 5. - Sorting maps at Jandía isthmus for August 1996 and February 1997.
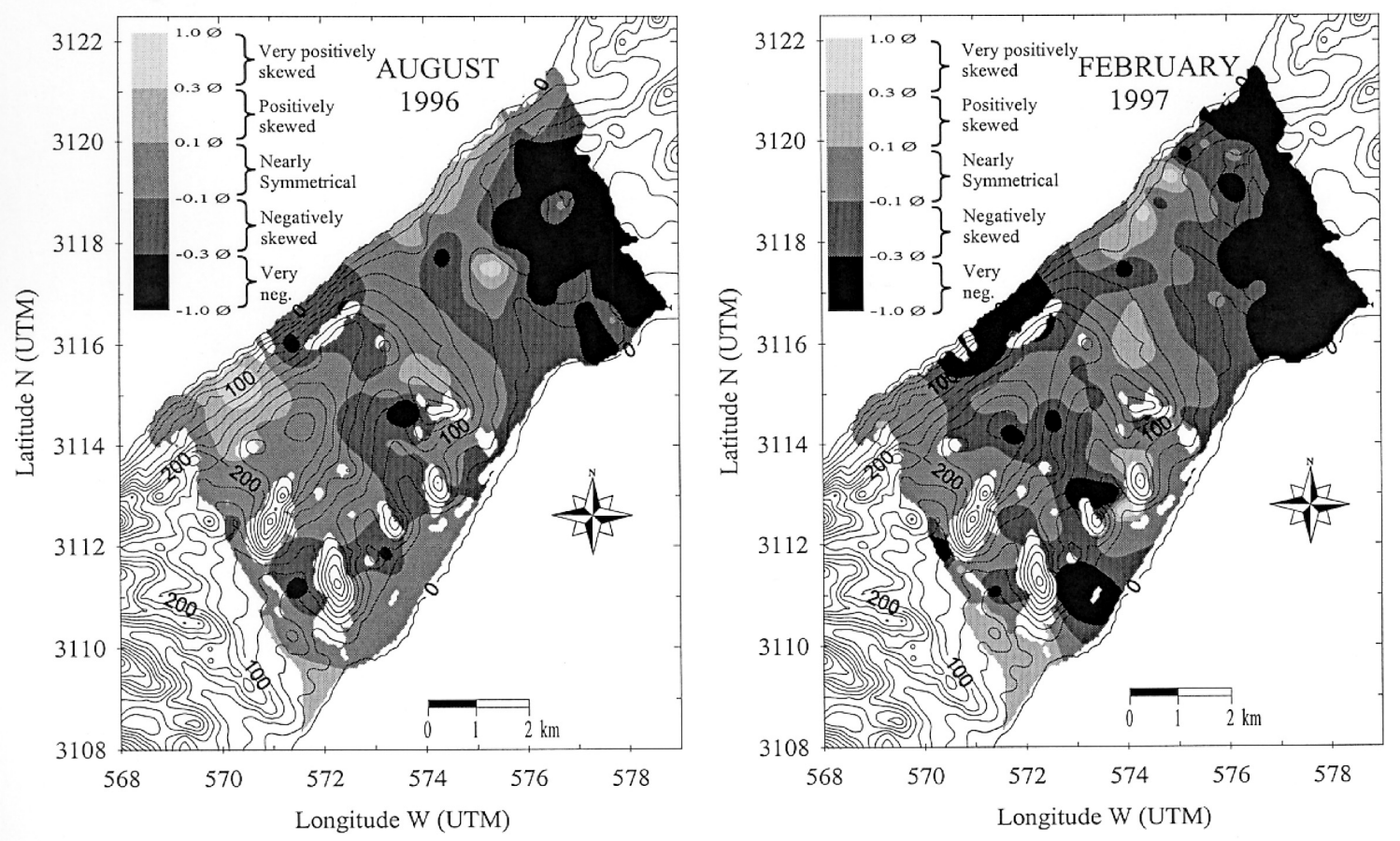

FIG. 6. - Skewness maps at Jandía isthmus for August 1996 and February 1997.

Carbonate content of the medium sand fraction is very high for all the samples, but there is a spatial gradient with more carbonate from the northeast to the southwest (Fig. 8). A general increase of $4.4 \%$ in carbonate content from August 1996 to February 1997 has also been identified (Table 1 and 3 ). Coarse mode data have not been used for the maps because it is only present in few samples with basalt and carbonate crust fragments. Therefore, carbonate content in this fraction is very variable but generally lower (Table 1). 

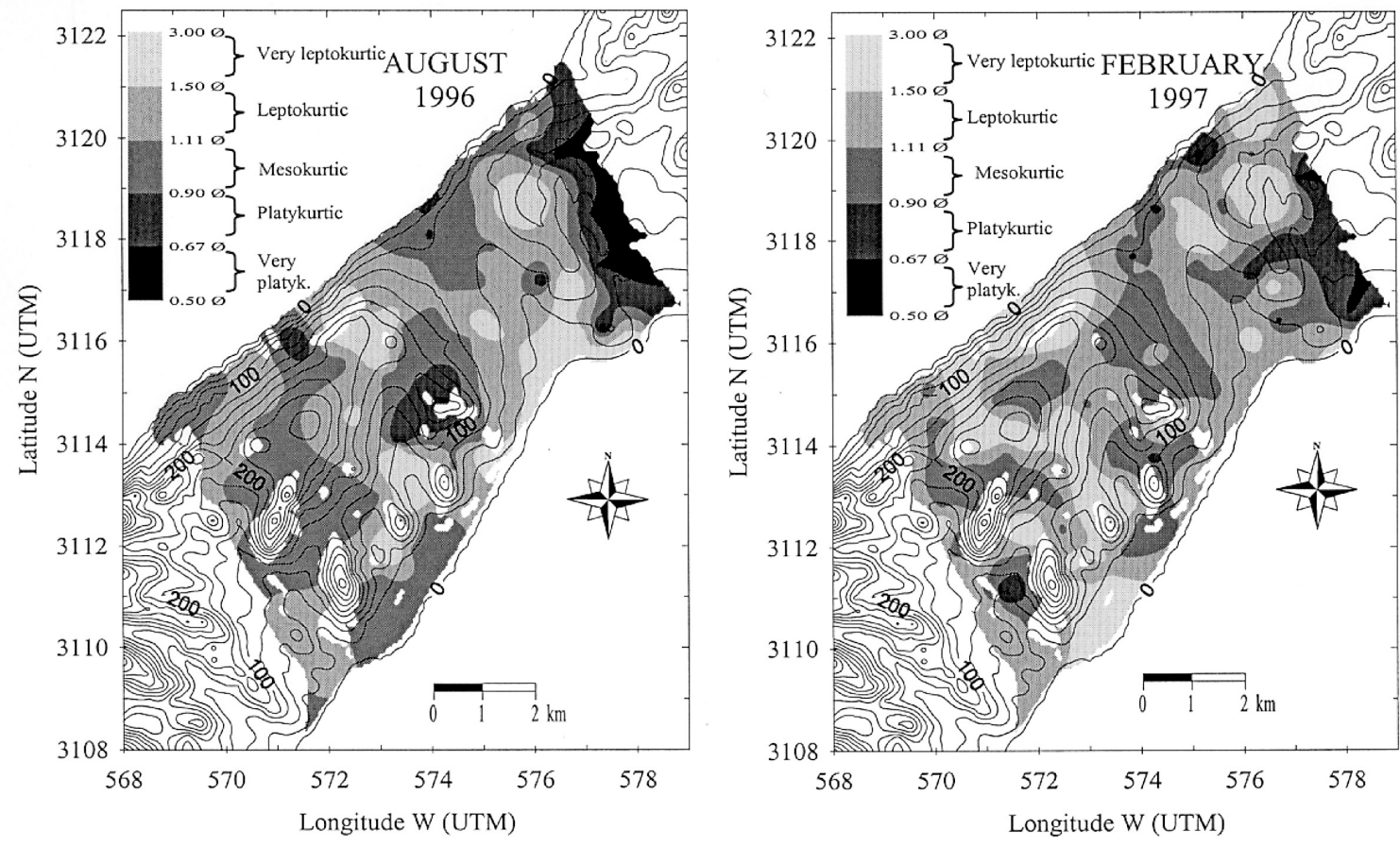

FIG. 7. - Kurtosis maps at Jandía isthmus for August 1996 and February 1997.
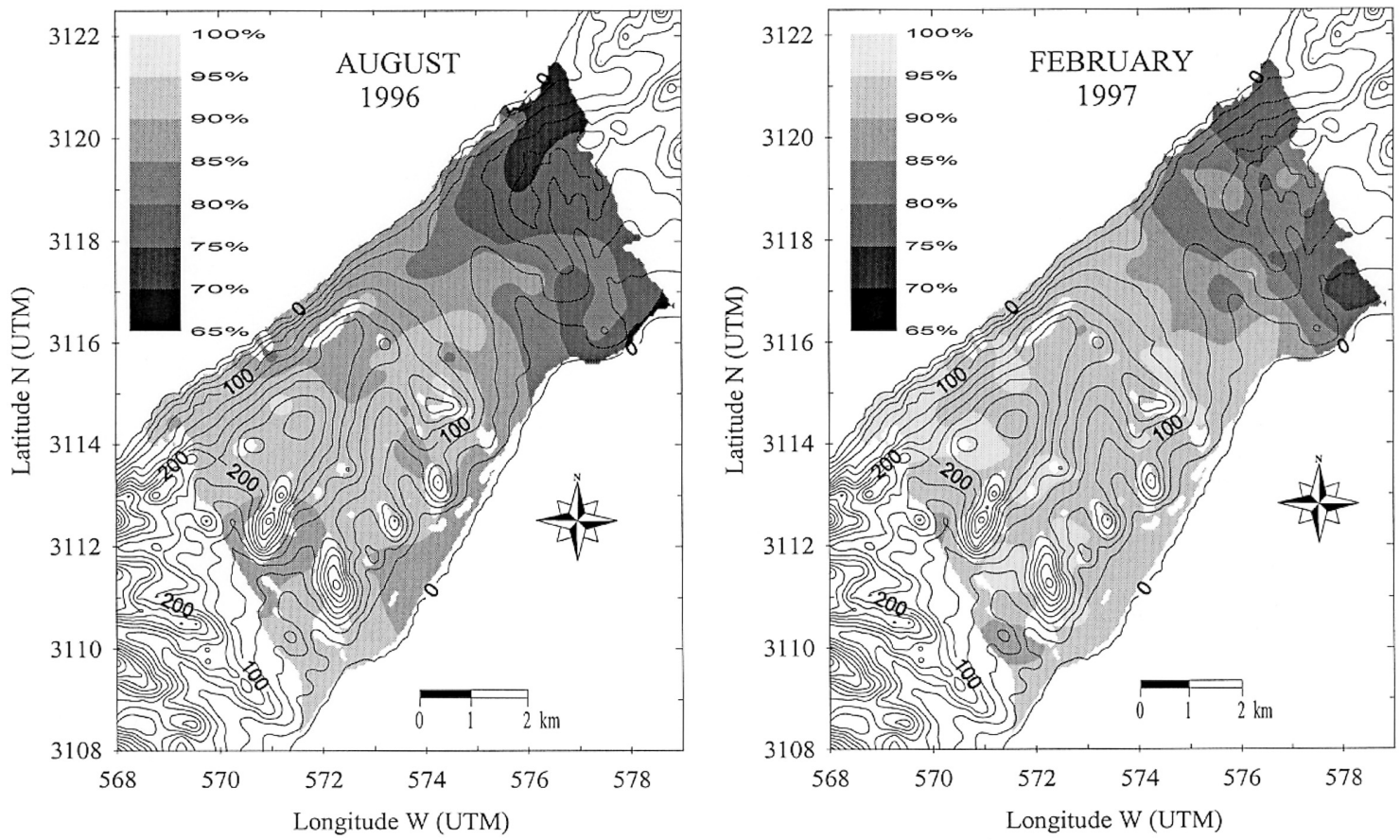

FIG. 8. - Carbonate content maps at Jandía isthmus for August 1996 and February 1997.

Altogether, this sedimentary cartography differentiate three zones in the isthmus from their sediment characteristics: $i$ ) The northeastern zone of the Isthmus, near Costa Calma resorts. Aeolian surface sediments are coarse, poorly sorted, and negatively skewed sands, whose kurtosis values ranged from very leptokurtic to very platikurtic. This area has the lowest carbonate content. ii) The southwestern zone of the isthmus is composed of medium, well or middle sorted, symmetrical or positively skewed, and mesokurtic sands. It presents the highest carbonate content. iii) The rest of the isthmus consists of many 
TABLE 3. - Percentage of surface associated with each $5 \%$ carbonate content interval.

\begin{tabular}{lrc}
\hline Carbonate content (\% wt) & August 1996 & February 1997 \\
\hline $95-100$ & 0.68 & 13.16 \\
$90-95$ & 38.22 & 51.98 \\
$85-90$ & 29.94 & 12.19 \\
$80-85$ & 11.28 & 12.25 \\
$75-80$ & 14.17 & 8.96 \\
$70-75$ & 5.45 & 1.46 \\
$65-70$ & 0.26 & 0.00 \\
\hline
\end{tabular}

little sub-zones, but it is not possible to define their limits due to the high variability of the five sedimentary parameters.

On the other hand, seasonal variations have also been identified for sorting, skewness, kurtosis, and carbonate content but not for mean grain size. Samples of February are more poorly sorted, more negatively skewed, more leptokurtic and their carbonate content is higher. However, differences between the northeastern and southwestern zones are clear in both periods.

\section{Mathematical meaning of PCA factors}

First (F1) and second (F2) factors have been extracted from the PCA, explaining 52.1\% and $21.2 \%$ of total variability respectively. Figure 9 shows the relation between initial variables and extracting factors. Values of these two factors and the initial sedimentary variables have been employed in the MRA. Results are the equations I and II for F1 in August 1996 and February 1997 respectively, and equations III and IV for F2 in the same months:

$$
\begin{aligned}
& \mathrm{F} 1=0.62 \mathrm{M}_{\mathrm{z}}-0.68 \sigma_{\mathrm{I}}+1.38 \mathrm{Sk}_{\mathrm{I}}-0.01 \mathrm{~K}_{\mathrm{G}}+2.99 \cdot \mathrm{C}-2.67 \\
& \mathrm{~F} 1=0.62 \mathrm{M}_{\mathrm{z}}-0.70 \sigma_{\mathrm{I}}+1.32 \mathrm{Sk}_{\mathrm{I}}-0.19 \mathrm{~K}_{\mathrm{G}}+3.46 \mathrm{C}-2.92 \\
& \mathrm{~F} 2=-0.58 \mathrm{M}_{\mathrm{z}}+0.36 \sigma_{\mathrm{I}}-0.53 \mathrm{Sk}_{\mathrm{I}}+1.00 \mathrm{~K}_{\mathrm{G}}+15.53 \mathrm{C}-13.02 \\
& \mathrm{~F} 2=0.68 \mathrm{M}_{\mathrm{z}}-0.02 \sigma_{\mathrm{I}}-0.98 \mathrm{Sk}_{\mathrm{I}}+1.58 \mathrm{~K}_{\mathrm{G}}+5.30 \mathrm{C}-7.94
\end{aligned}
$$

Where mean size $\left(\mathrm{M}_{\mathrm{z}}\right)$, sorting $\left(\sigma_{\mathrm{I}}\right)$, skewness $\left(\mathrm{Sk}_{\mathrm{I}}\right)$, and kurtosis $\left(\mathrm{K}_{\mathrm{G}}\right)$ are expressed in phi $(\phi)$ units while carbonate content $(\mathrm{C})$ has one as $100 \%$.

Considering the statistical significance of each one of the factors, and taking into account that F1 coefficients are very similar between them, but not those of $\mathrm{F} 2$, we propose a new equation $(\mathrm{V})$, which is an average of (I) and (II) equations.

$$
\mathrm{F} 1=0.62 \mathrm{M}_{\mathrm{z}}-0.69 \sigma_{\mathrm{I}}+1.35 \mathrm{Sk}_{\mathrm{I}}-0.10 \mathrm{~K}_{\mathrm{G}}+3.25 \mathrm{C}-2.85
$$

Equation (V) is an alternative to PCA and MRA combined analysis to calculate F1 for future studies with few samples or without a wide aeolian environmental diversity. Note that wind regime has been considered in equation (V) since it is an average of equations (I) and (II), which represent summer and winter conditions respectively. Since there is an equivalent number of samples in each study period (109 samples in summer and 132 in winter), the
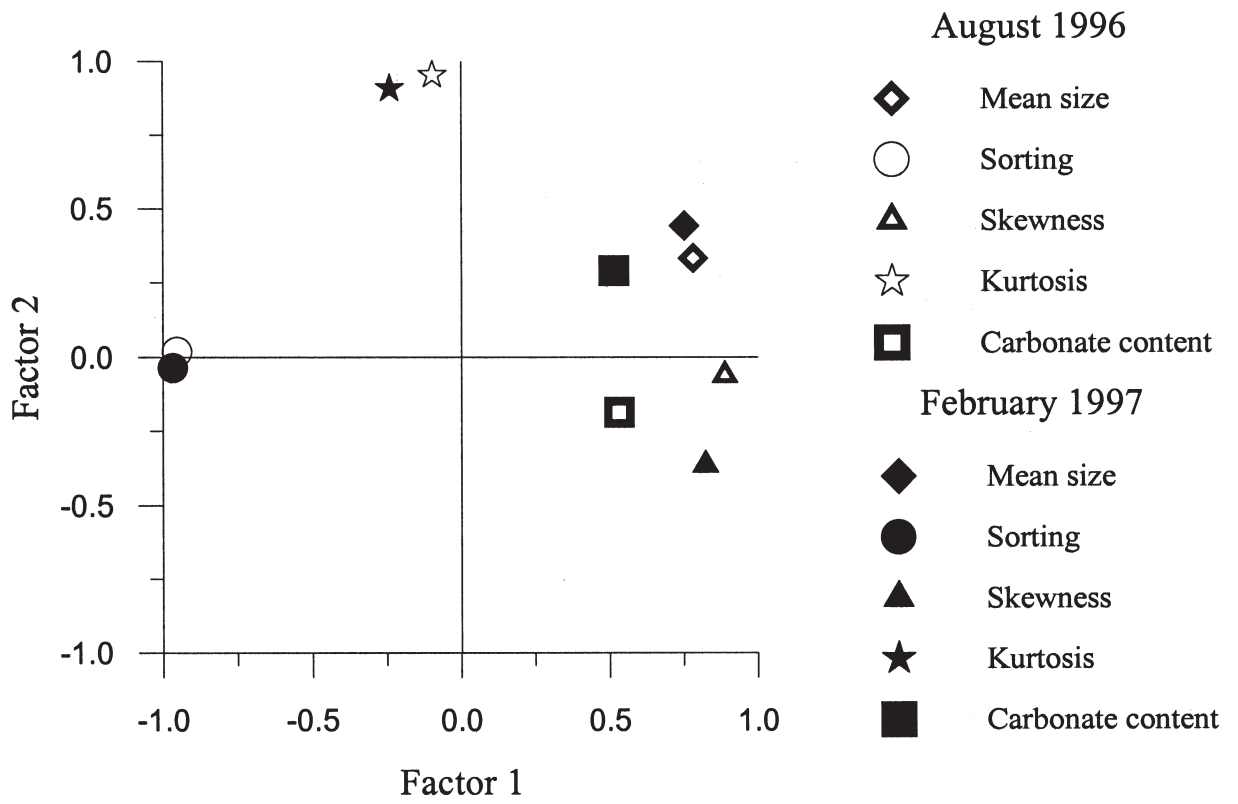

FIG. 9. - Dispersion diagram of statistical factors and sedimentary variables is very similar in both study periods. 
result of applying PCA and MRA combined analysis only once to all the samples should have been nearly the same as equation (V).

A strong mathematical relationship has been found between F1 and the three former textural parameters and the carbonate content, but the influence of kurtosis is negligible in both study cases. Therefore, finest sizes, best sorted, most positively skewed and highest carbonate contents of the sediments contribute to positive values of F1.

\section{DISCUSSION}

\section{Sedimentological meaning of the statistical factors}

Cros and Serra (1993) applied a PCA method to combine the sedimentary information for a complex dune system, using the carbonate content and seven different grain-size fractions. In Jandía, carbonate content has been also considered, but grain-size parameters have been chosen instead of grain-size fractions to combine the result with the interpretation of the sedimentary cartography.

Mean size, sorting, skewness, and density are sedimentary parameters related to the ability of sediments to be blown. Since spatial and temporal variations of these four parameters can be mathematically reflected in the F1 values, it seems that the first

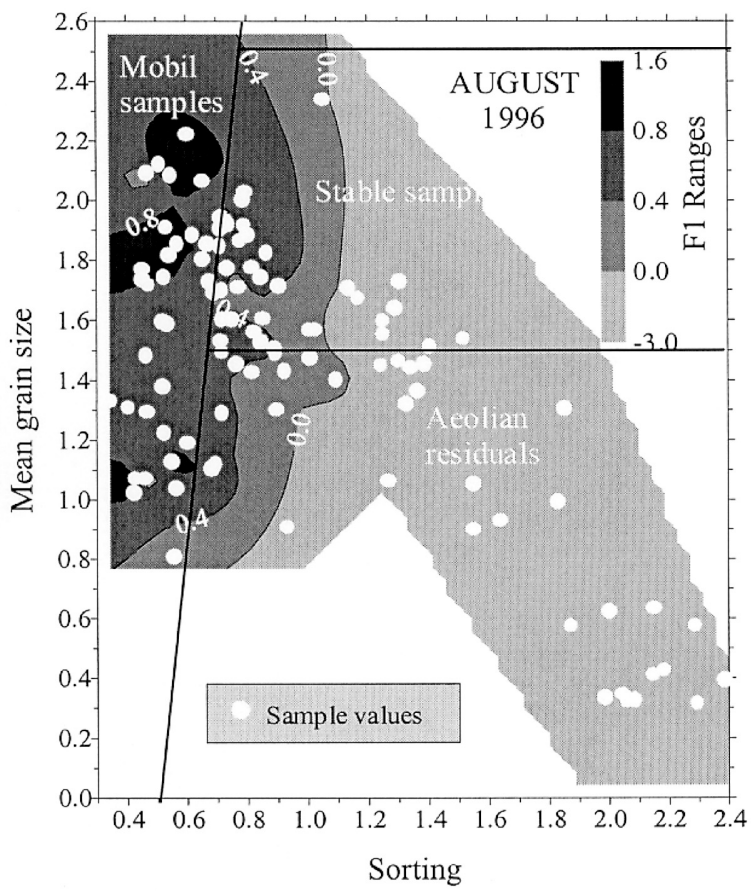

factor will be closely related to the high or low aeolian sediment availability. The second factor was not successful, since it is mainly related to carbonate content and kurtosis (eq. III and IV). Consequently, only the former factor is applicable for analysis.

Gläser's (1984) diagram identifies samples of aeolian mobility, aeolian stability, and aeolian residuals for each study period. This sediment classification is also reflected in their grain-size distributions. Aeolian mobility samples have only one mode ( $2 \phi$ fraction) and the smallest grain size ranges; aeolian stable samples present a bimodal distribution, with the main mode in $2 \phi$ and the second one in $3 \phi$; and finally, aeolian residuals correspond to polymodal samples, with previous and other modes in 0.5 and $-3 \phi$, as the widest grainsize ranges (Fig. 3).

F1 values have been compared with Gläser results to evaluate their physical meaning. Most of the samples characterised as aeolian residuals according to Gläser (1984) criteria present negative values of F1, as well as some of the stable samples (Fig. 10). On the other hand, the higher positive values of F1 are located in the aeolian mobility sector. Nevertheless, some samples with positive values of F1 are not included in the stable samples sector and even a few of them lay in the aeolian residuals domain. It has been verified that most of these particular samples proceed from sand sheets deposits, and consequently they are mobil sediments.

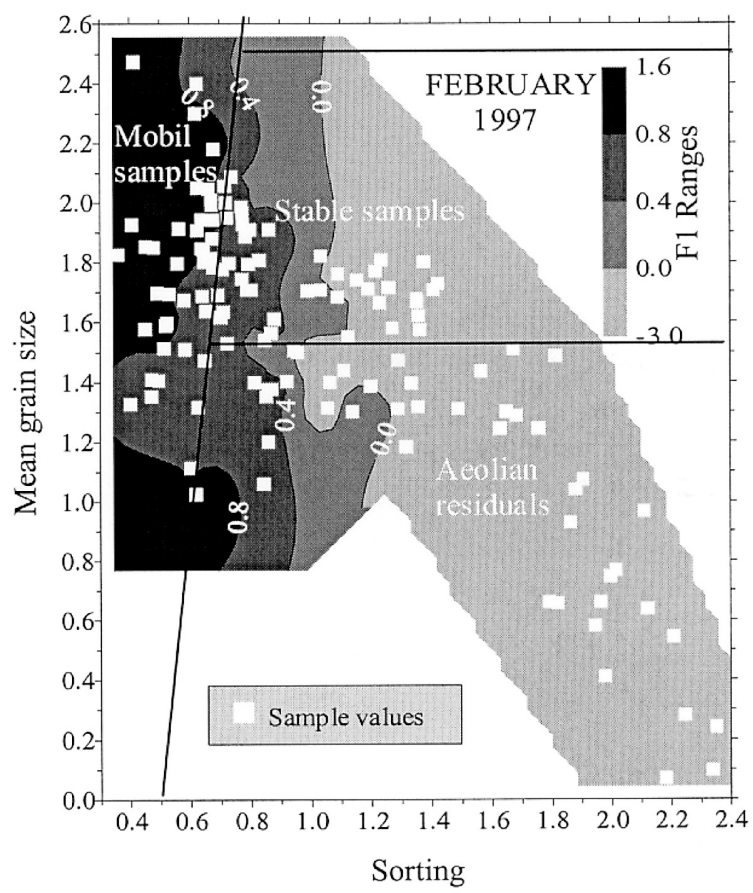

FIG. 10. - Gläser's (1984) diagram for the samples of each study period and Factor 1 classification ranges. 

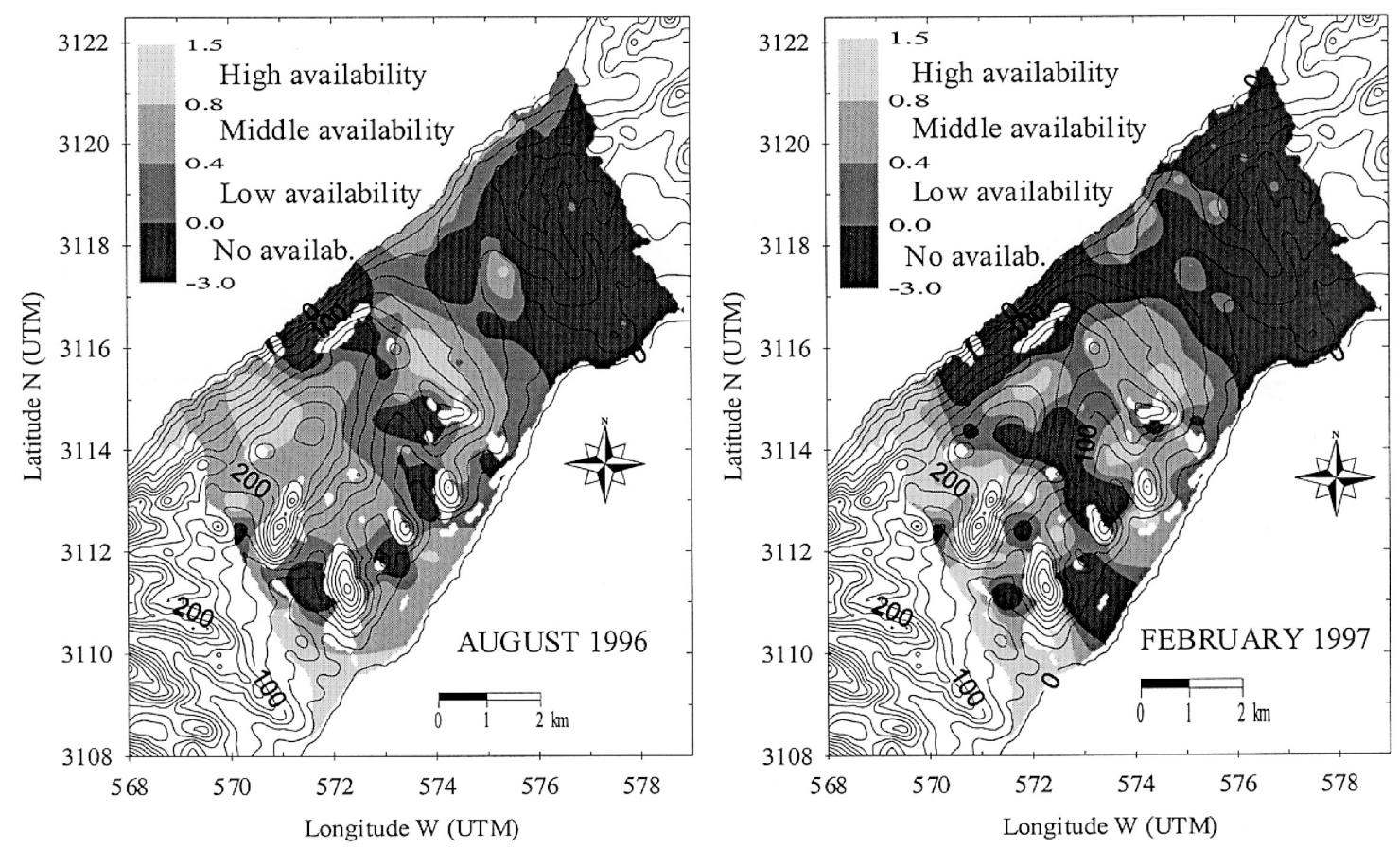

FIG. 11. - Maps of eolian sediment availability estimated from textural and compositional parameters at Jandía isthmus for August 1996 and February 1997.

The reason for the differences between F1 and Gläser is because F1 factor is related to the properties of the sediments that define their ability to be remobilized, and not only to grain size and sorting. The better fitting of aeolian samples to their real environment permits us to call F1 factor as the Aeolian Sediment Availability (ASA) parameter, and we suggest the next classification criteria: negative $A S A$ values means very low availability of aeolian sediments, and consequently no aeolian transport will take place except under the influence of extremely strong winds. Values from 0 to 0.4 are for a low aeolian sediment availability, and strong winds are necessary to move this material. ASA values between 0.4 and 0.8 correspond to areas covered by the appropiate sediments to be blown under relatively intense winds, and ASA values higher than 0.8 are indicative of samples with the most relevant sediments to be transported by weak winds.

ASA maps have been plotted at Jandía isthmus for August 1996 and February 1997 (Fig. 11). The spatial zones described are now confirmed: $i$ ) The northeastern area presents low or very low availability of aeolian sediments, as well as other zones near the Agua Oveja hill in the windward side and Lomas Negras hill in the leeward side (see figure 2 for location). ii) Conversely, the highest avail- ability of sediments is located both at the southwestern zone and the Huesos del Caballo hillsides, in the centre of the study area.

The more important seasonal variation is the increase of surface without sediments available to be blown in winter, while at summer time areas with middle and high ASA parameters are larger (Table 4).

\section{Grain size interpretation of aeolian environments}

Jandía isthmus presents an extensive diversity of aeolian environments, with ancient and present deposits involved in the actual aeolian processes. Spatial differences in the wind speed are not important, but transport intensity ranges very much among the aeolian environments (Alcántara-Carrió, 1999). This fact suggests that the degree of sediment availability is associated with different kinds of isthmus

TABLE 4. - Clasification criteria and surface isthmus percentage for the Aeolian Sediment Availability parameter.

\begin{tabular}{lccc}
\hline \multicolumn{2}{l}{ Aeolian sediment availability } & August 1996 & February 1997 \\
\hline High & $0.8<A S A$ & 9.85 & 13.75 \\
Middle & $0.4<A S A \leq 0.8$ & 30.44 & 19.78 \\
Low & $0<A S A \leq 0.4$ & 22.75 & 17.78 \\
Very low & $A S A \leq 0$ & 36.97 & 48.69 \\
\hline
\end{tabular}


surface deposits. Sand transport processes in the isthmus must be mainly controlled by the availability or scarcity of sediments. Previous studies in the area which focus on bedforms and macro-scale processes cannot detect all the aeolian environmental variability (Criado, 1991). Present work is based on grain or micro-scale analysis (Clemmensen, 1993). Finest and best sorted sediments are more easily blown (Bagnold, 1941), and positive skewed values are typical of mobile aeolian environments (Friedman, 1961). On the other hand, density of sediments is related to their threshold shear stress to be blown, and therefore carbonated sands will be more easily blown than basalt ones because of their lower density.

Grain size distributions of surface sediments present many spatial and seasonal variations for the different aeolian environments: serir areas have abundant pebbles of basalt and/or carbonate crust fragments, mixed with sand; well-sorted sediments of medium to fine sand size are associated with reversing (windward) and falling (leeward) dunes; while sand sheet deposits have intermediate granulometric properties. However, the main mode identified at 2 $\varnothing$ fraction for all the grain size distributions (see Fig. 3) is in the typical size of blown sands (Bagnold, 1941), which suggests that blown sediments cover the entire isthmus surface, although different grain size distributions indicate that the aeolian process is not produced with the same characteristics and intensity in the whole area.

Sand is coarser at the windward side than at the leeward one, because it is exposed to stronger winds. This means also that trade winds prevail over eastern and southern winds at the net annual balance. Sediments of the northeastern zone are poorly sorted, which combined with their coarser grain sizes indicate that they will be hardly blown, while particles at the southwestern and central areas of the isthmus are finer and better sorted and consequently, more appropiated to be blown, especially in the occidental limit and during the trade winds period.

Regarding skewness, positive values predominate in the south-eastern zone and near Huesos del Caballo hill, specially during the trade winds period. These samples are characteristic of aeolian dune and ripple forms (Friedman, 1961). Serir deposits have negative skewed values because aeolian sand is retained in between coarser materials, which produce polymodal samples defined as aeolian residuals (Besler, 1983). Finally, sand sheets have symmetrical values (near to 0 ) because they are less mobile than dunes due to the partial stabilisation for the vegetal cover. Therefore, predominance of negative and symmetrical values suggests that serir and sand sheet deposits are the majority in the isthmus, instead of dune deposits, although small vegetated dunes are superimposed on sand sheets in many areas. Relation between kurtosis and other grainsize parameters, carbonate content, or sedimentary characteristics of the deposits has not been found. However, kurtosis has been considered in the PCA to avoid missing information about the aeolian sediment availability, although, as has been shown in the results, this is the less important variable in defining the ASA parameter.

\section{Source areas and supply of sediments}

Mineralogical analyses of the Jandía sediments distinguished between silicates and carbonates (Höllermann, 1990; Meco, 1993). Former ones are mainly rock and mineral fragments eroded from basaltic outcrops of the Jandía shield (17 to 14.2 Ma, Coello et al., 1992). Biogenic sediments consist of skeletal calcareous algae, echinoderm spines, shell fragments and foraminifera tests (Höllermann, 1990). Therefore, carbonate content provides information about the different compositional properties in each sample. X-ray diffraction analyses and foraminifera assemblages showed that dunar deposits of Upper Pleistocene are the main source of materials for the actual aeolian dynamics (Alcántara-Carrió et al. 2000a, 2000b). Since ancient and modern dune deposits basically consist of bioclastic fragments, high carbonate content in present sediments indicates a higher erosion and contribution from the source areas. Eroded sediment from ancient deposits are accumulated at the surface in winter and will be remobilised during the next trade winds period (Alcántara-Carrió, 1999).

Moreover, carbonate content can be considered an index of the density of materials, since only silicates and carbonates have been identified in the area, and density is lower for carbonated materials than for basaltic ones. As has been stated by Iversen et al. (1976), the threshold velocity is directly related to grain density, so that the less dense materials will be remobilized with lower wind velocities. It means, for example, that excluding the influence of any other factor, aeolian transport of the medium sand fraction will be more intense at the northwestern zone, where materials are the richest in carbonate content. Finally, the coarser mode presents very variable carbonate content (Table 1), because it is 
composed of basalt and carbonate crust fragments. However, their size avoids mobilisation from local winds.

\section{Environmental factors influence}

Environmental factors, such as vegetation, topographic slope and surface moisture content, also affect aeolian dynamics in coastal areas. Thus, vegetation traps particles and extracts momentum from the wind (Wolfe and Nickling, 1993), affects dune forms (Hack, 1941), critical shear stress of sediment transport (Hesp, 1981), and roughness length (Bressolier and Thomas, 1977). Moisture content of the sediments increases cohesion between particles, making both entrainment and transport difficult (Sherman, 1990; Nickling, 1994). Windward slopes restrict sediment transport, while leeward slopes increase it (Hardisty and Whitehouse, 1988).

Influence of these factors over the aeolian processes is indirectly reflected in the sediment properties of the surface deposits, and consequently in the ASA parameter. Vegetal cover produces stabilisation of sediments and bimodal samples. General topography of the isthmus, between Jandía and Betancuria massifs (see Fig. 2), generates high wind velocity in this lower and narrow area. Slope differences between both sides favour transport in the leeward side and to the lee beaches during trade wind periods, but also favour it in the windward side of the isthmus and to the windward coast during episodes of easterly and southerly winds. Finally, and due to the high isolation, intense winds and scarcity of showers at the study area, influence of moisture content over aeolian dynamics seems to be negligible except for few days during the year.

\section{CONCLUSIONS}

F1 factor has been named the Aeolian Sediment Availability (ASA) parameter because it shows a lineal relation with all the grain-scale parameters affecting the availability of aeolian sediments. Four main advantages can be obtained from the use of ASA parameter instead of the graphic diagrams of Friedman (1961), Besler (1983) and Gläser (1984):

1) This new parameter considers the influence of more sedimentary parameters that determine the ability of sediments to be blown. Conversely, the above grain-size diagrams only consider mean grain-size and sorting parameters. Equation V shows that ASA parameter will be higher, and so will be the aeolian sediment transport if there is an adequately energetic wind, not only with small and well sorted grains, but also with those positively skewed and less dense.

2) The ASA parameter is not only a result of grain-size and compositional data of aeolian particles from different environments (coastal dunes, sand sheets and serir deposits), but also reflects of the wind regime, since coefficients of this parameter are an average of summer and winter conditions at the study area.

3) There is a continuous gradient of ASA values indicative of environments where the sediments are able to be blown until places in which there are no aeolian particles. In Besler (1993) and Gläser (1994) graphic diagram samples could be just on the limit between mobile sediments and aeolian residuals, which is not very real.

4) The ASA parameter is a numerical parameter which ranges continuously, while the graphic diagrams classify the samples into three discrete groups. Moreover, it allows interpolation methods with the parameter values for each sample in order to obtain the spatial distribution maps at the study area.

Maps of the ASA parameter for August 1996 and February 1997 represent the spatial and seasonal variations of the sediment availability, and consequently the aeolian dynamics. Increase of carbonate content during winter in the mobile sand sheet and dune deposits of the southwestern zone is reflected as a higher $A S A$ value. Nevertheless, altogether middle and high ASA surface is higher in August. Northeastern zone has the lower ASA values because coarser materials generate high roughness and restricts sand transport.

Aeolian sediment availability maps are consistent with the seasonal behaviour of the wind patterns, vegetal cover, and moisture content, which altogether favour higher net aeolian sand transport during summer periods. Moreover, maps of figure 11 are consistant with empirical sand trap studies, since the highest transport rates have been recorded in the Pecenescal wadi, i.e. the southwestern limit of the isthmus, and in the central zone (Alcántara-Carrió et al., 1996; Alcántara-Carrió, 1999). Apart from that, main dune forms are located in surfaces with high values of the ASA parameter: reversing dunes in the windward side and falling dunes in the limit with the lee beaches. Aeolian flux diagram, deduced from geomorphologic and preliminary sand traps 
data (Alcántara-Carrió et al., 1996), ratifies present maps made from the ASA parameter.

It is important to note that grain-size characteristics should be employed as an indicator of the sediment availability, for example by means of the ASA parameter, instead of sediment mobility, as proposed by Besler (1983) and Gläser (1984). Sediment mobility and their aeolian transport intensity will depend on both availability of the appropiate sediments and local wind conditions.

To summarize, the ASA concept is a new sedimentary parameter deduced from textural and compositional properties of the sediments, which shows the availability of sediments to be blown from the surface of different aeolian environments and presents several advantages over previous graphic methods. This concept has universal applicability, but obviously the coefficients given in equation (V) are restricted to areas with similar characteristics to the one that has been here presented. For future research, definition of the ASA parameter could be likely improved if real measurements of specific gravity instead of carbonate content were employed, and moisture surface content should also have to be considered in other study areas. Finally, future research is also neccesary to test the classification ranges that have been here established.

\section{ACNOWLEDGEMENTS}

This work has been supported by research projects 1/94 from University of Las Palmas de Gran Canaria and 1/95 from Consejería de Educación, Cultura y Deportes of the Canarian Government. The authors are also thankful to the anonymous referees for their critical review and constructive comments.

\section{REFERENCES}

Alcántara-Carrió, J. - 1999. Dinámica sedimentaria eólica en el Istmo de Jandía. Modelización y cuantificación del transporte. $\mathrm{Ph}$. D. Thesis, Univ. Las Palmas de G. C., 330 pp.

Alcántara-Carrió, J., P. Diz, I. Alejo, G. Francés, I. Alonso and F. Vilas. - 2000a. Contenido en foraminíferos de los depósitos eólicos del Istmo de Jandía (Fuerteventura). Geogaceta, 27: 195-198.

Alcántara-Carrió, J., S. Fernández-Bastero, I. Alejo, I. Alonso and F. Vilas. - 2000b. Caracterización mineralógica e identificación de las áreas fuentes de los sedimentos actuales del Istmo de Jandía (Fuerteventura). Geogaceta, 27: 199-202.

Alcántara-Carrió, J., I. Alonso, L. Hernández, E. Pérez-Chacón and L.E. Romero. - 1996. Landscape evolution and human alterations of the aeolian dynamics in the Jandía Isthmus (Fuerteventura, Spain). In: J. Taussik and J. Mitchell (eds.),
Partnership in Coastal Zone Management, pp. 283-290. Samana Publishing Ltd., Cardigan.

Alonso, I., J. Alcántara-Carrió, I. Montesdeoca-Sánchez and G. Bidegaín. - 1998. Characteristics of aeolian sediments at Jandía Isthmus (Fuerteventura). In: J.C. Cañaveras, M.A. García del Cura and J. Soria (eds.), 15th Int. Sedimentological Congress: Sedimentology at the dawn of the third millenium. Alicante, pp. 130-131.

Bagnold, R.A. - 1941. The physics of blown sand and desert dunes. Metheuen. London.

Bagnold, R.A. - 1956. Flow of cohesionless grains in fluids. Phil. Trans. R. Soc. London, series A, 249: 235-297.

Bauer, B.O., D.J. Sherman, and J.F. Wolcott. - 1992. Sources of uncertainty in shear stress and roughness length estimates derived from velocity profiles. Professional Geographer, 44 (4): 453-464.

Bennet, S.J. and J.L. Best. - 1995. Mean flow and turbulence structure over fixed two-dimensional dunes: implications for sediment transport and bedform stability. Sedimentology, 42: 491-513.

Besler, H. - 1983. The response diagram: distinction between aaeolian mobility and stability of sands and aeolian residuals by grain size parameters. Zeitschr.f. Geomorph. N. F. Supp., 45: 287-301.

Bressolier, C.F. and Y. Thomas. - 1977. Studies on wind and plant interactions on French Atlantic coastal dunes. J. Sed. Petrol. 47: 331-338.

Calero, R. and J.A. Cartas. - 1990. Estimación de la capacidad energética eólica de la isla de Fuerteventura. Ed. Excmo. Cabildo Insular de Fuerteventura, $255 \mathrm{pp}$

Clemmensen, L.B. - 1993. Short Course Notes. Geologisk Institut, Kobenhavns Univ.

Coello, J., J.M. Cantagrel, F. Hernán, J.M. Fuster, E. Ibarrola, E. Ancoechea, C. Casquet, C. Jamond, J.R. Díaz de Terán and A. Cendrero. - 1992. Evolution of the eastern volcanic ridge of the Canary Islands based on new K-Ar data. J. Volcanol. Geoth. Res., 53: 251-274.

Criado, C. - 1991. La evolución del relieve de Fuerteventura. Servicio de publicaciones del Excmo. Cabildo Insular de Fuerteventura, $318 \mathrm{pp}$.

Cros, L and J. Serra. - 1993. A complex dune system in Baix Empordà (Cataluña, Spain). In: K. Pye (ed.), The dynamics and environmental context of aeolian sedimentary systems. pp. 191199. Geol. Soc. Sp. Publ. 72.

Dingler, R.U., A. Warren, and A.S. Goudie. - 1992. Theoretical and measured aeolian sand transport on a barrier island, Louisiana, U.S.A. Sedimentology, 39: 1031-1043.

Folk, R.L. and W.C. Ward. - 1957. Brazos river bar. A study in the significance of grain size parameters. J. Sed. Petrol., 27: 3-26.

Frank, A. and G. Kocurek. - 1994. Effects of atmospheric conditions on wind profiles and aeolian sand transport with an example from white sands national monument. Earth Surface Processes and Landforms, 19: 735-745.

Friedman, G.M. - 1961. Distinction between dune, beach, and river sands from their textural characteristics. J. Sed. Petrol., 31: 514-520.

Friedman, G.M. and J.E. Sanders. - 1978. Principles of Sedimentology. Ed. John Wiley \& Sons. New York, $792 \mathrm{pp.}$

Fryberger, S.G. and G. Dean. - 1979. Dune forms and wind regime. In: E.D. McKee (ed.), A study of global sand seas, pp. 137-169. Geol. Survey Prof. Paper 1052. Washington.

Gläser, B. - 1984. Quantitative untersuchungen zur morphogenese und mobilität des Alt-dünenkomplexes in der Provinz Weiber Nil. In: H. Mensching (ed.), Beiträge zur morphodynamik im Relief des Jebel-Marra-Massivs und in seinem Vorland (Darfur / Republik Sudan). pp. 202-217. Akad. d. Wissench. Göttingen, Hamburg.

Guitián, F. and T. Carballas. - 1976. Técnicas de análisis de suelos. Pico Sacro, Santiago de Compostela.

Hack, J.T. - 1941. Dunes of the western Navajo country. Geog. Rev. 31: 240-263.

Hardisty, J. and R.J.S. Whitehouse. - 1988. Evidence for a new sand transport process from experiments on Sahara dunes. Nature, 332: 532-534.

Hesp, P.A. - 1981. The formation of shadow dunes. J. Sedim. Petrol. 51: 101-112.

Hesp, P.A. and K. Hastings. - 1998. Width, height and slope relationships and aerodynamic maintenance of barkhans. Geomorphology, 22: 193-204. 
Höllermann, P. - 1990. Zur geoökodinamic von dünen: eine fallstudie aus süd-Fuerteventura (Kanarische Inseln). Geoökodinamik, 11 (2-3): 213-240.

Horikawa, K., S. Hotta and N. Kraus. - 1986. Literature review of sand transport by wind on a dry sand surface. Coastal Eng., 9: 503-526.

Howard, A.D., J.B. Morton, M. Gad-El-Hack, and D.B. Pierce. 1978. Sand transport model of barchan dune equilibrium. Sedimentology, 25: 307-338.

Hsu, S.A. - 1973. Computing aeolian sand transport from shear velocity measurements. J. Geol. 81: 739-743.

Iversen, J.D., J.B. Pollack, R. Greeley and B.R. White. - 1976. Saltation threshold on Mars: the effect of intraparticle force, surface roughness and low atmospheric density. Icarus, 29: 381-393.

Lancaster, N. - 1986. Grain-size characteristics of linear dunes in the southwester Kalahari. J. Sed. Petrol., 56 (3): 395-400.

Le Roux, J.P. - 1994. A spreadsheet template for determining sediment transport vectors from grain-size parameters. Сотри. Geosci. 20: 433-440.

Meco, J. - 1993. Testimonios paleoclimáticos en Fuerteventura. Tierra y Tecnología, 6: 41-48.
Nickling, W.G. - 1994. Aeolian sediment transport and deposition. In: K. Pye (ed): Sediment transport and depositional processes, pp. 293-350. Blackwell Sc. Publ.

Reineck, H.-E. and I.B. Singh. - 1980. Depositional sedimentary environments, 2nd. Ed., Springer-Verlag, $551 \mathrm{pp}$.

Sarre, R.D. - 1988. Evaluation of aeolian sand transport equations using intertidal zone measurements, Saunton Sand, England. Sedimentology, 35: 671-679.

Sherman, D.J. - 1990. Discussion: evaluation of aeolian sand transport equations using intertidal-zone measurements, Saunton Sands, England. Sedimentology, 37: 385-392.

Sherman, D.J. and S. Hotta. - 1990. Aeolian sediment transport: theory and measurements. In: K.F. Nordstrom, N. Psuty and B. Carter (eds.), Coastal dunes, form and process. pp. 17-37. John Wiley \& Sons. Chichester.

Wasson, R.J. and R. Hyde. - 1983. Factors determining desert dune type. Nature, 304: 337-339.

Willians, S.H. and J.A. Lee. - 1995. Aeolian saltation transport rate: an example of the effect of sediment supply. J. Arid Env., 30: 153-160.

Wolfe, S.A. and W.G. Nicling. - 1993. The protective role of sparse vegetation in wind erosion. Progr. Phis. Geog. 17: 50-68. 